\title{
Sensitivity and Specificity of Difficult Airway Parameters at Asella Teaching and Referral Hospital, Oromia Regional State, Ethiopia
}

\author{
Tahir Aman Worji ${ }^{1, ~ *, ~ A b d u r a h m a n ~ T u n e ~ D e d e c h o ", ~ G e t a h u n ~ M o l l a ~ S h o n k a ~}{ }^{2}$, \\ Melese Meleku Kuruche ${ }^{3}$, Mohammed Suleiman Obsa ${ }^{4}$ \\ ${ }^{1}$ Department of Anesthesia, Arsi University, Asella, Ethiopia \\ ${ }^{2}$ Department of Surgery, Wolaita Soddo University, Wolaita Soddo, Ethiopia \\ ${ }^{3}$ Department of Nursing, Woliata Soddo University, Wolaita Sodo, Ethiopia \\ ${ }^{4}$ Department of Anesthesia, Wolaita Soddo University, Wolaita Soddo, Ethiopia
}

Email address:

tahirastu@gmail.com (T. A. Worji)

${ }^{*}$ Corresponding author

\section{To cite this article:}

Tahir Aman Worji, Abdurahman Tune Dedecho, Getahun Molla Shonka, Melese Meleku Kuruche, Mohammed Suleiman Obsa. Sensitivity and Specificity of Difficult Airway Parameters at Asella Teaching and Referral Hospital, Oromia Regional State, Ethiopia. International Journal of Clinical and Experimental Medical Sciences. Vol. 6, No. 4, 2020, pp. 60-64. doi: 10.11648/j.ijcems.20200604.12

Received: June 7, 2020; Accepted: June 17, 2020; Published: July 17, 2020

\begin{abstract}
Background: Maintenance of a patent airway is a primary responsibility of anesthesiologists. The difficulty of achieving a patent airway varies with anatomical and other individual factors, and identification of the patient with a difficult airway is vital in planning anesthesia management so that endotracheal intubation and positive pressure ventilation can be achieved safely. Institutional based crossectional study design was conducted using systematic random sampling technique. Regular supervision and follow up was made. Sensitivity, specificity, positive and negative predictive value was calculated to confirm presence of difficulty airway. A total of 184 patients who underwent surgery under general anaesthesia were included into the study. The mandibular protrusion test, the use of stylet, neck mobility and mouth opening $<30 \mathrm{~mm}$ are the airway parameters found to the most sensitive tests. The combination of bedside airway parameters to predict difficult airway showed that Mallampati classes III \& IV, Mandibular protrusion mouth opening $<30 \mathrm{~mm}$, attempt $>3$, and ineffective alternative technique were strongly associated with difficulty airway.
\end{abstract}

Keywords: Difficult Airway, Sensitivity, Specificity, General Anesthesia, Airway Management, Asella

\section{Background}

Maintenance of a patent airway is a primary responsibility of anesthesiologists. The difficulty of achieving a patent airway varies with anatomical and other individual factors, and identification of the patient with a difficult airway is vital in planning anesthesia management so that endotracheal intubation and positive pressure ventilation can be achieved safely.

Difficult mask ventilation (DMV) may occur before attempting intubation or may occur after intubation failure [1]. The ability to ventilate and oxygenate a patient using a bag-mask breathing system may be lifesaving in the case of failure of the initial intubation attempt in the decisional algorithms published by the American Society of Anesthesiologists Task Force [2].

The historical information, physical examination findings, and radiological features associated with a difficult airway are well established. Proposed airway assessment scales vary from the simple to the complex, which are impractical as a clinical tool. The physical characteristics associated with difficult intubation include obesity, head and neck movement, jaw movement, receding mandible, buck teeth (long upper incisors), Mallampati scores, maxillary incisor characteristics, male sex, age decreased mouth opening, shortened thyromental distance, and short neck importance [3].

An assessment system that objectively measures factors 
associated with a difficult intubation in the resuscitation room needs to be simple and suitable to perform on obtunded patients, and easily remembered $[4,5]$. The fundamental responsibility of an anesthesiologist is to maintain adequate gas exchange through a patent airway. Failure to maintain a patent airway for more than a few minutes results in brain damage or death [6].

Extension of the head at the atlanto-occipital joint can be assessed by simply looking at the movements of the head, measuring the sternomental distance, or by using devices to measure the angle [7]. Mouth opening can be assessed by measuring the distance between upper and lower incisors with the mouth fully open. The ease of lifting the mandible can be assessed by comparing the relative position of the lower incisors in comparison with the upper incisors after forward protrusion of the mandible [8]. The measurement of the mentohyoid distance and Thyromental distance provide a rough estimate of the submandibular space. The ability of the patient to move the lower incisor in front of the upper incisor tells us about jaw movement [9].

Difficulty with airway management has potentially serious implications, as failure to secure a patent airway can result in hypoxic brain injury or death in a matter of minutes. Early recognition of a patient's suspected for difficult airway helps the clinician to plan the anesthetic management and to minimize the potential for serious airway-related morbidity [1]

Therefore the aim of this study is to determine sensitivity and specificity of difficult airway predictors among surgical patients who undergo general anesthesia and to determine predominant risk factors related to difficult airway.

\section{Methods and Materials}

\subsection{Study Area and Period}

The study was conducted at Asella Teaching and Referral Hospital. The hospital is found in Asella town which is the administrative city of eastern Arsi zone of Oromia region which is located approximately about $175 \mathrm{~km}$ away from Addis Ababa with an elevation of $2430 \mathrm{~m}$. It has subtropical highland climate; monthly temperature variation is very rare due to its relation close to the equator and the seasons are only distinguishing by the intensity of rain, which is most in August and least in December. It has one Governmental and three private Hospital. Asella Teaching and Referral Hospital has major departments like Gynecology and Obstetrics, Internal medicine, Surgery, Paedatrics and minor departments like dentistry and Ophtalmology. The period of survey was from July to August, 2018.

\subsection{Study Design}

A facility based crossectional study design was conducted.

\subsection{Study Population}

The study population was selected surgical patients, who undergo general anesthesia at Asella Teaching and Referral Hospital from July to August, 2018.

Sample size determination: The sample size is calculated using the single population proportion formula,

$$
\mathrm{n}=\mathrm{Z}^{2}(1-\alpha / 2) \mathrm{pq} / \mathrm{d}^{2}
$$

Formula components are:

1. $n=$ number of sample size.

2. $Z=$ desired $95 \%$ confidence, $Z=1.96$.

3. $p=$ percentage of difficulty airway $(23 / 80)=28.75 \%[10]$

4. $\mathrm{q}=1-\mathrm{p}$; for this study, we assumed maximum variability, hence $\mathrm{p}=0.2875 ; \mathrm{q}=1-\mathrm{p}=1-0.2875=0.7125$

5. $\mathrm{d}=$ absolute allowable error, $5 \%$ of Sample size.

By expecting $28.75 \%$ of overall at $95 \%$ confidence level, the result of formula computation is 315 . Since the midyear population (2520) is less than 10,000, I use correction formula which is $n f=n / 1+n / N$ where $n$ is calculated sample size and $\mathrm{N}$ is population size. From this the total population within one month was 420=accordingly, $\mathrm{nf}=\mathrm{n} / 1+\mathrm{n} / \mathrm{N}=315 / 1+315 / 420=180 . \quad$ Adding $5 \%$ for contingency, the total sample size becomes 189 .

Sampling Technique: Simple random sampling technique was used $t$ select study participants until sample size achieved.

\subsection{Data Collection Technique and Data Quality Control Assurance}

Data was collected using pretested structured questionnaire after reviewing relevant literatures and assessing the Internet sources. It was prepared in English first and translated to Oromic and Amharic and again back translation to English was made to check for consistency. Data collectors and supervisors was trained on each items included in the study tools. During data collection, regular supervision and follow up was be made.

\subsection{Data Analyzing and Processing}

The data was entered on Epi info version 7 and was exported to SPSS version 20 computer program for analysis. Descriptive statistics was used to summarize data, tables and figures for display results. Sensitivity and specificity was determined to detect presence of difficulty airways.

\subsection{Ethical Consideration}

Ethical clearance and approval was secured from Institutional Review Board, College of health science, Arsi University. Permission to conduct and Consent was obtained from Hospitals. Informed Verbal consent was also secured from every study participant. In case of study participant below 18yrs of age, parental consent was taken wherever available. Confidentiality and anonymity were ensured. They were asked for their willingness to participate in the study.

\section{Result}

\subsection{Comparative Analysis of Difficulty Airway Predictor Parameters}

The mandibular protrusion test, the use of stylet, neck mobility and mouth opening $<30 \mathrm{~mm}$ are the airway 
parameters found to the most sensitive tests and more predictors of difficulty airway $\{92.4 \%, 92.3 \%, 76.9$ and $69.2 \%$, respectively\}. On the Other hand, Rheumatoid arthritis, neuromuscular disease and short neck are the airway parameters found to the most specificity tests $\{93 \%, 92.4 \%$ and $88.9 \%$, respectively\}. Laryngoscope grade Mallampati scoring short neck Number of attempts Mandible protrusion test have higher area under the curve which showed good precision tests and they are associated with difficulty airway at p-value of less than 0.05 (Table 1).

Table 1. Comparative analysis of predictor parameters of airway among patients who underwent surgery at Asella Teaching and Referral Hospital, Ethiopia, $2018(n=184)$.

\begin{tabular}{|c|c|c|c|c|c|c|c|c|}
\hline \multirow{2}{*}{ Variable } & \multirow{2}{*}{$\begin{array}{l}\text { Sensitivity } \\
(\%)\end{array}$} & \multirow{2}{*}{$\begin{array}{l}\text { Specificity } \\
(\%)\end{array}$} & \multirow{2}{*}{ PPV (\%) } & \multirow{2}{*}{ NPV (\%) } & \multirow{2}{*}{$\mathbf{A U C}$} & \multirow{2}{*}{ P-value } & \multicolumn{2}{|c|}{$95 \%$ CI interval } \\
\hline & & & & & & & Upper & Lower \\
\hline Laryngoscope grade & 30.8 & 30.4 & 16.7 & 83.3 & .753 & 0.000 & .624 & .883 \\
\hline Mallampati scoring & 61.6 & 11.7 & 12.3 & 83.3 & .749 & 0.000 & .613 & .884 \\
\hline Obesity & $7.1 \%$ & 7.6 & 7.7 & 92.9 & .500 & .996 & .336 & .663 \\
\hline short neck & 30.8 & 88.9 & 30.8 & 82.6 & .402 & 0.039 & .226 & .577 \\
\hline Neck mobility & 76.9 & 70.6 & 6 & 81.2 & .577 & 0.056 & .402 & .753 \\
\hline Sleep apnea & 15.4 & 86 & 7.7 & 93 & .493 & 0.893 & .329 & .658 \\
\hline Neuromuscular disease & 7.7 & 92.4 & 7.1 & 92.9 & .500 & 0.991 & .336 & .663 \\
\hline Rheumatoid arthritis & 7.7 & 93 & 7.7 & 92.3 & .497 & 0.927 & .333 & .661 \\
\hline Number of attempts & 38.5 & 18.7 & 7.6 & 80 & .747 & 0.001 & .606 & .889 \\
\hline Mandible protrusion test & 92.4 & 3.5 & 15.3 & 83.3 & .600 & 0.047 & .435 & .765 \\
\hline Use of stylet & 92.3 & 53.2 & 13.3 & 91 & .266 & 0.05 & .154 & .378 \\
\hline Alternative to Intubate & 84.6 & 66.7 & 16.2 & 98.3 & .244 & 0.000 & .119 & .368 \\
\hline
\end{tabular}

\subsection{ROC Curve of Difficult Intubation and Airway Parameter}

The ROC curve in Figure 1 shows that Mallampati classification, Mandibular protrusion test, neck mobility and grade of lanrgoscopy tests are above the reference line and are more consistent to sensitivity and 1 - specificity line and also with an increased area under the curve compared to the combined and the remaining airway tests (figure 1).

\section{ROC Curve}

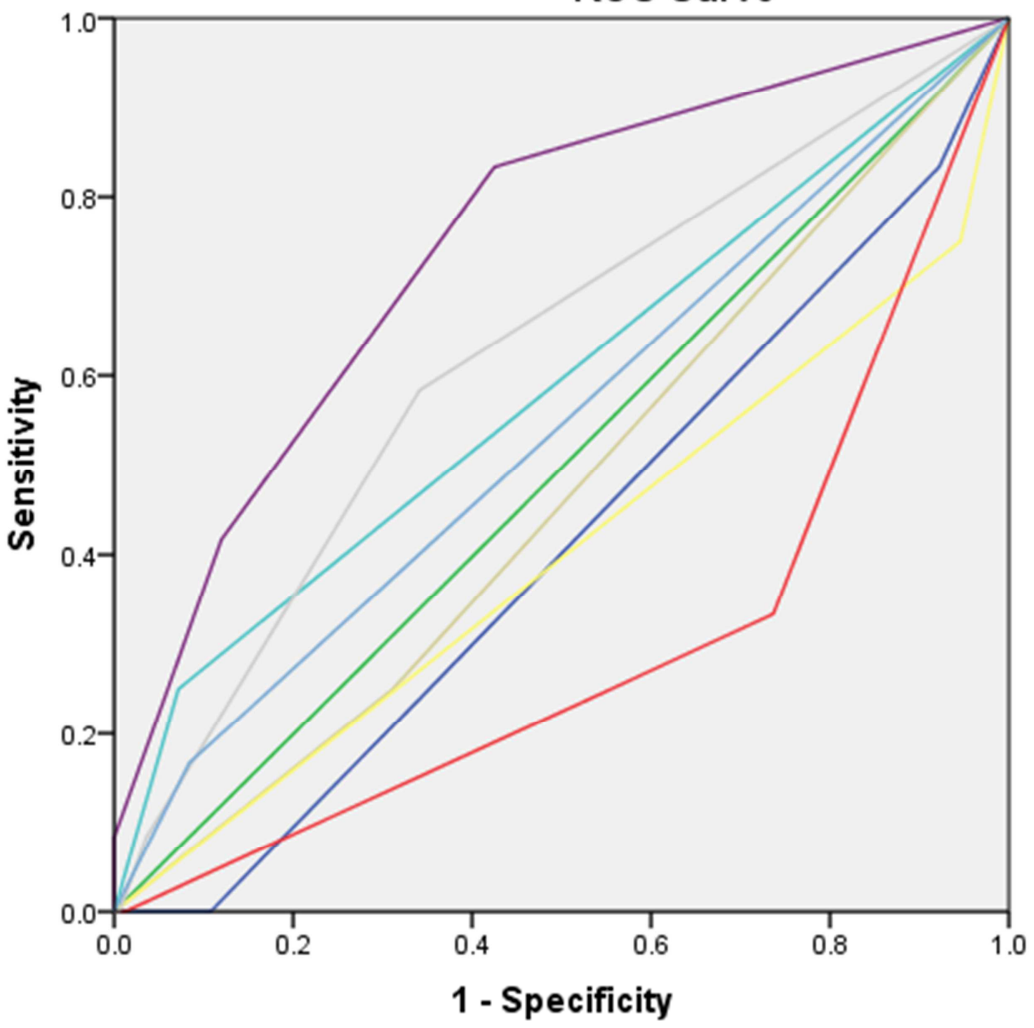

Source of the Curve

$$
\begin{aligned}
& \text { - age category } \\
& \text { - BMICATEGORY } \\
& \text { - TYPE OF SURGERY } \\
& \text { - mallampaticlassification } \\
& \text { thyromentaldistance } \\
& \text { - mouthopening } \\
& \text { - moblityoftheneck } \\
& \text { - mandibularprotrutiontest } \\
& \text { - cormackandlehanelaryngoc } \\
& \text { opygrading }
\end{aligned}
$$

Diagonal segments are produced by ties.

Figure 1. ROC curve of difficult intubation and airway parameter of airway among patients, who underwent surgery at Asella Teaching and Referral Hospital from July to August, 201. 


\section{Discussion}

It is widely accepted that general anesthesia is not without morbidity. One of the well-known life threatening events associated with general anesthesia is difficult airway which can happen during induction of anesthesia while attempting to insert the endotracheal tube with the aid of laryngoscope [11]. According to the result of this study, Mallampati classification, Mandibular protrusion test, neck mobility and grade of lanrgoscopy tests are above the reference line and are more consistent to sensitivity and 1 - specificity line. But none of them has $100 \%$ sensitivity. Similarly, another study found that there is still no single test with $100 \%$ sensitivity and specificity to predict difficult Laryngoscope and intubation [12]. The neck circumference to temporomandibular distance is a better indicator of difficult airway in obese patients [3].

In this review it was found that the combined airway screening test study done on prediction of difficult Laryngoscope failed to show higher detection of subjects with difficulty in Laryngoscope and intubation than other single screening tests which agrees with other finding [3]. In addition, the findings of a multicentre methodological study demonstrated that combining tests did not improve those results.

A study conducted in Gonder surgical hospital showed the most important predominant risk factors of difficulty airway are Mallampati classes III \& IV, mouth opening < $30 \mathrm{~mm}$, JSD grade C, attempt $>3$, and ineffective alternative technique [13]. Generally, different parameters for the prediction of difficult airways have been studied. Similar to the current study, restriction of head and neck movement and decreased Mandibular space have been identified as important predictors in other studies [5]. Although Mallampati classification has been reported to be a good predictor in this study, it is found to be of limited value by other [14]. Interincisor gap, forward movement of jaw and Thyromental distance have produced variable results in predicting difficult airways in previous studies $[15,16]$.

\section{Conclusion}

The mandibular protrusion test, the use of stylet, neck mobility and mouth opening $<30 \mathrm{~mm}$ are the airway parameters found to the most sensitive tests $\{92.4 \%$, $92.3 \%, 76.9$ and $69.2 \%$, respectively $\}$. The combination of bedside airway parameters to predict difficult airway showed that Mallampati classes III \& IV, Mandibular protrusion mouth opening $<30 \mathrm{~mm}$, attempt $>3$, and ineffective alternative technique were strongly associated with difficulty airway.

\section{Funding}

Not available.

\section{Abbreviations}

DA: Difficulty airway; AU: Arsi University.

\section{Competing Interests}

The authors declare that they have no competing.

\section{Authors' Contributions}

TA has contributed to the conception, design of the study, data acquisition, data entry, analyzing and interpretation of the data, and drafted and revised the manuscript. MS, GM, AT and MM has contributed to the conception and assisted in the initial design of the study, analyzed and interpreted the data and critically revised the manuscript. Both authors read and approved the final manuscript.

\section{Acknowledgements}

We would like to thank all the study participants.

\section{References}

[1] Ark S-H, Park H-P, Jeon Y-T, Hwang J-W, Kim J-H, et al. (2010) A comparison of direct laryngoscopic views depending on pillow height. Journal of anesthesia 24: 526-530.

[2] Merah N, Foulkes-Crabbe D, Kushimo O, Ajayi P (2004) Prediction of difficult laryngoscopy in a population of Nigerian obstetric patients. West African journal of medicine 23: 38-41.

[3] Kim W, Ahn H, Lee C, Shin B, Ko J, et al. (2011) Neck circumference to thyromental distance ratio: a new predictor of difficult intubation in obese patients. British journal of anaesthesia 106: 743-748.

[4] El-Ganzouri AR, McCarthy RJ, Tuman KJ, Tanck EN, Ivankovich AD (1996) Preoperative airway assessment: predictive value of a multivariate risk index. Anesthesia \& Analgesia 82: 1197-1204.

[5] Arne J, Descoins P, Fusciardi J, Ingrand P, Ferrier B, et al. (1998) Preoperative assessment for difficult intubation in general and ENT surgery: predictive value of a clinical multivariate risk index. British journal of anaesthesia 80: 140146.

[6] Rose DK, Cohen MM (1994) The airway: problems and predictions in 18,500 patients. Canadian Journal of Anaesthesia 41: 372-383.

[7] Khan ZH, Kashfi A, Ebrahimkhani E (2003) A comparison of the upper lip bite test (a simple new technique) with modified Mallampati classification in predicting difficulty in endotracheal intubation: a prospective blinded study. Anesthesia \& Analgesia 96: 595-599.

[8] Savva D (1994) Prediction of difficult tracheal intubation. British journal of anaesthesia 73: 149-153. 
[9] Mallampati S, Gatt S, Gugino L, Desai S, Waraksa B, et al. (1986) A Clinical Sign to Predict Difficult Tracheal Intubation: A Prospective Study. Obstetric Anesthesia Digest 6: 257.

[10] Mallat J, Robin E, Pironkov A, Lebuffe G, Tavernier B. Goitre and difficulty of tracheal intubation; 2010. Elsevier. pp. 436-439.

[11] Katz JA (2012) 4th National Audit Project of the Royal College of Anaesthetists and The Difficult Airway Society Major Complications of Airway Management in the United Kingdom. Anesthesiology: The Journal of the American Society of Anesthesiologists 116: 496-496.

[12] Basaranoglu G, Columb M, Lyons G (2010) Failure to predict difficult tracheal intubation for emergency caesarean section. European Journal of Anaesthesiology (EJA) 27: 947-949.
[13] Workeneh SA, Gebregzi AH, Denu ZA (2017) Magnitude and predisposing factors of difficult airway during induction of general anaesthesia. Anesthesiology research and practice 2017.

[14] Lee A, Fan LT, Gin T, Karmakar MK, Kee WDN (2006) A systematic review (meta-analysis) of the accuracy of the Mallampati tests to predict the difficult airway. Anesthesia \& Analgesia 102: 1867-1878.

[15] Butler P, Dhara S (1992) Prediction of difficult laryngoscopy: an assessment of the thyromental distance and Mallampati predictive tests. Anaesthesia and intensive care 20: 139-142.

[16] Bilgin H, Ozyurt O (1998) Screening tests for predicting difficult intubation. A clinical assessment in Turkish patients. Anaesthesia and intensive care 26: 382. 